\title{
Disparity in the risk of exposure to respirable crystalline silica dust among non-manual and manual employees in the construction industry
}

\author{
Ben Fluck ${ }^{1}$ - Lamine Mahdjoubi ${ }^{1}$ - David Fluck ${ }^{2}$. Christopher H. Fry ${ }^{3}$ Thang S. Han ${ }^{4,5}$ (D)
}

Received: 3 June 2021 / Revised: 17 July 2021 / Accepted: 19 July 2021 / Published online: 30 July 2021

(C) The Author(s) 2021

\begin{abstract}
Construction workers are at increased health risk due to exposure to respirable crystalline silica (RCS) dust. We examined differences in health risk among non-manual and manual employees in the construction industry. The participants were drawn randomly from the construction industry by targeting UK construction workers' websites. Online survey of construction industry employees using a questionnaire consisted of 17 items to obtain information on demographic data, employment history and health risk exposure. Chi-squared tests were used to explore differences in health risk between manual and non-manual employees, and logistic regression to determine the risk of adverse events in manual workers. Of the 47 employees invited, 45 completed the questionnaire (95\% response rate). Seventeen were non-manual (professional, project managers and managers) and 28 were manual employees (tradesmen and construction workers). There was a significantly higher percentage of non-manual employees below 45 years than older group $\left(70.6 \%\right.$ vs $\left.39.3 \% ; \chi^{2}=4.2, p=0.039\right)$ and they worked less than 20 years than those working longer $\left(82.4 \%\right.$ vs $\left.32.1 \% ; \chi^{2}=10.7, p=0.001\right)$. Compared to non-manual workers, manual workers were more likely to work $>20$ years: $\mathrm{OR}=2.2(95 \% \mathrm{CI}=1.3-3.6)$; be exposed to RCS dust and smoke: unadjusted $\mathrm{OR}=1.8$ (1.1-3.1), age and length of time working in construction industry adjusted $\mathrm{OR}=2.2(1.2-4.2)$; and have breathing problems: unadjusted $\mathrm{OR}=3.9(1.5-10.4)$, age, smoking and length of time working in construction industry adjusted $\mathrm{OR}=3.7(1.1-12.5)$. The risk of breathing problems was increased among individuals working more than 20 years: $\mathrm{OR}=4.8(1.2-18.6)$, exposed to dust and smoking: unadjusted $\mathrm{OR}=3.8(1.0-14.1)$, age and length of time working in construction industry adjusted $\mathrm{OR}=5.4$ (1.2-24.4), whilst those with adequate information on health hazards were associated with lower risk of breathing problems. There is an increased risk of exposure to RCS dust and pulmonary symptoms among manual employees in the construction industry. Further efforts are required to provide greater protection for this group of workers to reduce their health risk.
\end{abstract}

Keywords Occupational hazards $\cdot$ Healthcare inequality $\cdot$ Pulmonary disease $\cdot$ PPE $\cdot$ Smoking

Abbreviated title Risk of exposure to RCS

Thang S. Han

thang.han@rhul.ac.uk

1 Department of Architecture and the Built Environment, University of the West of England Bristol, Bristol, UK

2 Department of Cardiology, Ashford and St Peter's NHS Foundation Trust, Chertsey GU9 0PZ, UK

3 School of Physiology, Pharmacology and Neuroscience, University of Bristol, Bristol BS8 1TD, UK

4 Department of Endocrinology, Ashford and St Peter's NHS Foundation Trust, Chertsey GU9 0PZ, UK

5 Institute of Cardiovascular Research, Royal Holloway University of London, Egham TW20 0EX, UK

\section{Introduction}

Silicosis is a lung disease resulting from the inhalation of respirable crystalline silica (RCS) mineral dust that is found in stone, rocks, sands and clays. Occupational exposure to large amounts of RCS dust over time may be potentially fatal and irreversible. This fibrotic lung disease is one of the most prevalent occupational diseases, and has a long latency period (Leung et al. 2012; Greenberg et al. 2007). The main dusts on construction sites predominantly originate from concrete, silica, asbestos, cement, wood, stone and sand (van Thienen and Spee 2008), which are generated by drilling, blasting and grinding down certain materials such as stone and rocks (Akbar-Khanzadeh and Brillhart 2002; Flanagan et al. 
2003). These fragmented materials are released and circulated as 'airborne' dust particles, and are readily inhaled.

The Health and Safety Executive reported that, after asbestosis, silicosis is the second biggest health risk to construction workers (HSE 2021). RCS is a known potent toxin and a risk factor in the development of non-malignant respiratory and kidney diseases, as well as lung cancer (Steenland et al. 2001; Steenland and Sanderson 2001; OSHA 2016) with its associated mortality (Rice et al. 2001). Over the past decade there have been 10 to 20 deaths per year from occupational lung disease, and in 2019 a UK parliamentary inquiry was launched to scrutinise the impact of silicosis on the health and wellbeing of construction workers.

The degree of severity of silicosis is influenced by the type of dust, duration of exposure, as well as the concentration and size of the airborne dust particles (Leung \& Yu, 2012). While employees in the construction industry are at high risk of silicosis, there are differences in their risks of exposure. In this study, we examined the health risk disparity between non-manual (professional, project managers and managers) and manual employees (tradesmen and construction workers) in the construction industry including: duration of exposure to silica dust; the use of personal protective equipment (PPE) provision; lifestyle; and knowledge of health and safety risks, including the extent of awareness in the workplace and of symptoms of lung disease.

\section{Methods}

\section{Questionnaire design}

The questionnaire, designed to answer the question posed by the hypothesis, consisted of closed questions to maximise completeness of response from participants, and to reflect a wide range of their personal opinions, experiences and information that each participant has experienced in their careers. The questions covered a range of occupational-related information including: demographics; occupational background; duration of risk of exposure to silica dust, exposure to dust; tobacco smoking; and availability and use of PPE. In addition, the awareness of a number of aspects pertaining to this disease were examined, including awareness of silicosis, information on health hazards, health checks provided by the company, and pulmonary symptoms (Table 1).

\section{Participants and data collection}

The participants were drawn randomly from the construction industry by targeting UK construction workers' websites. Data were collected using an online questionnaire delivered through social media. The questionnaire was open online for one month and advertised over UK-based Facebook, Twitter
Table 1 The questionnaires
A. Demographics
1. "What age category do you fall into: 18-24, 25-34, 35-44, 45-54, $>55$ ?"
2. "Are you male or female, or prefer not to say?"
B. Occupational background
3. "Do you work as a: Professional (architect, engineer, executive), Project manager (managing more than 10 people), Manager (managing less than 10 people, Tradesman (electrician, carpenter, brick layer), Construction worker"
4. "Do you work for a company with more than 1000 employees?"
C. Length of time working in construction industry
5. "How long have you worked in the construction industry for: 0-5, 5-10, 10-20, > 20 years?"

\section{Exposure to dust and smoking}

"Do you often work in dusty environments?

7. "Do you smoke?"

\section{E. Personal protective equipment}

8. "Is Personal protective equipment (PPE) always provided when on site, e.g. breathing masks, helmets, gloves, safety goggles" Yes, No, Don't know

9. "Do you always make use of PPE equipment when you are working on site in a dusty environment?" Yes, No,

10. "If someone is not using PPE in a dusty environment, would you suggest they put it on?" Yes, No

\section{F. Awareness of silicosis}

11. "Have you ever heard of silicosis and what it is?" Yes, No

12. "Have you or anyone you know ever been diagnosed with silicosis?" Yes, No

\section{G. Information on health hazards}

13. "Are there adequate safeguards to ensure that you take protective action when working with silica dust from rock/concrete cutting and drilling?" Yes, No, Don't know

14. "Do you believe there is adequate education in place for you as an employee to recognise breathing health hazards?"Yes, No, Don't know

\section{H. Health checks}

15. "Does your company provide you with regular health checks?"Yes, No, Don't know

\section{Pulmonary symptoms}

16. "Have you ever suffered from breathing problems?"

and Reddit construction pages with subscribers ranging from 8000 to 25,000 . As this is an observational study to identify significant risk factors for a larger study, and since there exist no previous studies of this type in this area of research, the sample size could not be predetermined. Therefore 50 cases was felt to be a reasonable target given a wide range of questions collected over a period of one month of online survey.

\section{Risk factors}

The risk factors considered to be associated with occupational status comprised: the length of time working in the construction industry; exposure to dust and smoking; personal protective equipment; awareness of silicosis; information on health 
hazards; regular health checks provided by the company; and working for a company with $>1000$ employees.

\section{Statistical analysis}

Chi-squared tests were used to explore differences in outcome measures between manual and non-manual employees and risk factors relating to breathing problems. Multiple stepwise logistic regression was used to assess the relative risk of breathing problems. Results are expressed as odds ratios (OR) and 95\% confidence intervals (CI). We chose IBM SPSS Statistics for Windows, V.25.0 (IBM Corp, Armonk, NY, USA) as this statistics tool allows complex statistical analyses of survey data.

\section{Ethics and general data protection regulation (GDPR)}

Participants were fully informed about the background, purpose and objectives of the research. Participants consent and willingness to participate in the research was sought, and their right to withdraw at any stage of the survey was also clarified. This study complies with the University of the West of England, Bristol GDPR policy, including the importance of ensuring that participants' information is kept safe, and used only for the purpose of the research, as well as destroyed at the end of the study.

\section{Results}

Figure 1 shows the flowchart of the process for the paper construction from the point of literature review to data collection. Of 47 employees who responded, 45 completed the questionnaire (95\% response rate).

\section{Demographics and occupational background}

Nearly half of participants (48.9\%) were over 45 years old. There was only one female participant. Seventeen respondents were non-manual: $22.2 \%$ professional, $8.9 \%$ project managers and $6.7 \%$ managers, and 28 were manual employees: $33.3 \%$ tradesman, $28.9 \%$ construction workers.

\section{Exposure to dust and smoking}

A third (33.6\%) reported a history of smoking. Almost half of workers spent $>20$ years working in construction industry (indicating long duration of exposure to RCS), and 37.8\% worked for a large company. Three quarters (75.6\%) of workers reported that they often worked in dusty environments and a third (33.3\%) complained of breathing problems.

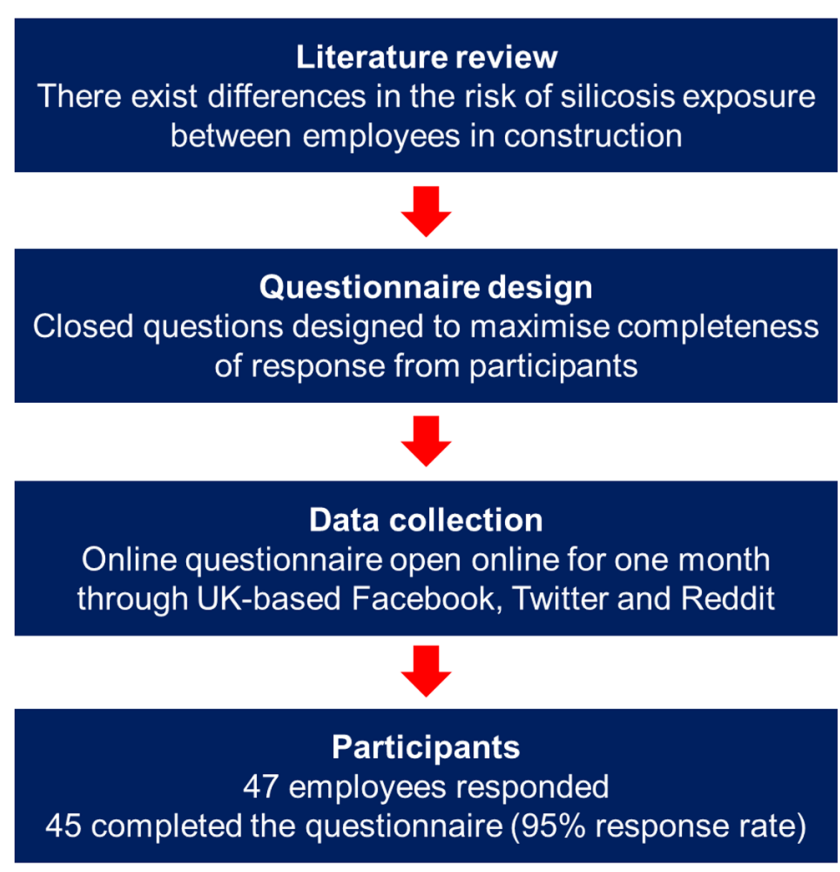

Fig. 1 Flowchart from the point of literature review to data collection

\section{Personal protective equipment}

Three quarters (75.6) of workers reported that PPE was always provided on site and $62.2 \%$ always made use of PPE when on site, $75.5 \%$ always advised others to use PPE in a dusty environment when they encountered someone not using it.

\section{Awareness of silicosis, information on health hazards and health checks}

Eighty percent of workers had heard of silicosis and nearly half (48.0\%) said there was adequate education on recognising breathing hazards. There were $57.8 \%$ of workers who reported that adequate safeguards were in place to ensure protective action could be taken when working with silica dust. Only $15.6 \%$ had had a diagnosis of silicosis and $26.7 \%$ had regular health checks provided by their employer. A third of patients complained of breathing problems (Table 2).

There was a significantly higher proportion of non-manual employees below 45 years than older group $(70.6 \%$ vs $39.3 \%$ ), and more of them than manual workers spending $\leq 20$ years working in construction industry $(82.4 \%$ vs $32.1 \%)$. Conversely, the proportion of manual workers below 45 years was lower compared to the older age group (29.4\% vs $60.7 \%$ ), and more of them spending $>20$ years working in construction industry than non-manual workers $(17.6 \%$ vs 67.9\%) (Fig. 2A \& B). There was also a higher percentage of manual workers reporting cigarette smoking $(5.9 \%$ vs $\left.53.6 \%, \chi^{2}=10.5, p=0.001\right)$, and often working in dusty environments (47\% vs $\left.92.9 \%, \chi^{2}=12.0, p=0.001\right)$. 
Table 2 Characteristics of the 45 employees in construction industry who responded to the questionnaire
Information gathered from questionnaire

Demographics

Age bands (years)

$18-24$

25-34

22.0

35- 44

17.8

$45-54$

26.7

55-64

22.2

Gender (male/female)

$97.8 / 2.2$

Occupational background

Non-manual employees

Professional (Architect, Engineer, Executive etc) 22.2

Project Manager (Managing more than 10 people) $\quad 8.9$

$\begin{array}{ll}\text { Manager (Managing less than } 10 \text { people) } & 6.7\end{array}$

Manual employees

Tradesman (Electrician, Carpenter, Brick Layer etc)

Construction worker 28.9

Working for company with >1000 employees 37.8

Length of time working in construction industry (years)

$0-5$

$5-10$

11.1

$10-20$

15.6

$>20$

Exposure to dust and smoking

Often working in dusty environment $\quad 75.6$

Smoking 33.6

Personal protective equipment

PPE always provided when on site $\quad 75.6$

$\begin{array}{ll}\text { Always make use of PPE when on site } & 62.2\end{array}$

$\begin{array}{ll}\text { Advising others to use PPE in dusty environment } & 75.5\end{array}$

Awareness of silicosis

Ever heard of silicosis $\quad 80.0$

Silicosis diagnosis self or someone known $\quad 15.6$

Information on health hazards

Adequate safeguards to ensure protective action is taken when working with silica dust $\quad 57.8$

There is adequate education on recognition of breathing hazards $\quad 48.9$

$\begin{array}{ll}\text { Regular health checks provided by company } & 26.7\end{array}$

Breathing problems 33.3
Compared to non-manual employees, there was a higher percentage of manual employees with a length of time working in construction industry of more than 20 years $(17.6 \%$ vs $\left.67.9 \%, \chi^{2}=10.7, p=0.001\right)$, working in a dusty environment and smoking $\left(5.9 \%\right.$ vs $\left.50.0 \%, \chi^{2}=9.3, p=0.002\right)$, and with breathing problems ( $0 \%$ vs $\left.53.6 \%, \chi^{2}=13.7, p<0.001\right)$. By contrast, there were fewer manual workers reported to have PPE provided by company, used or advised others to use PPE $\left(58.8 \%\right.$ vs $\left.28.6 \%, \chi^{2}=4.0, p=0.045\right)$, as well as adequate safeguards and education $\left(58.8 \%\right.$ vs $28.6 \%, \chi^{2}=4.0, p=$
0.045). There were no differences in awareness of silicosis, regular health checks provided by the company or if working for a company with $>1000$ employees (Table 3 ).

A similar pattern emerged for breathing problems. Compared with those who did not report breathing problems, the percentage of those reporting such problems were higher among employees with a length of time working in construction industry of more than 20 years $\left(36.7 \%\right.$ vs $73.3 \%, \chi^{2}=$ $5.4, p=0.020)$, working in dusty environment and who smoked $\left(23.5 \%\right.$ vs $\left.53.3 \%, \chi^{2}=4.1, p=0.044\right)$. By contrast, 
Fig. 2 Distribution of nonmanual and manual employees in different age groups (A) and length of time working in construction industry (B)
(A)

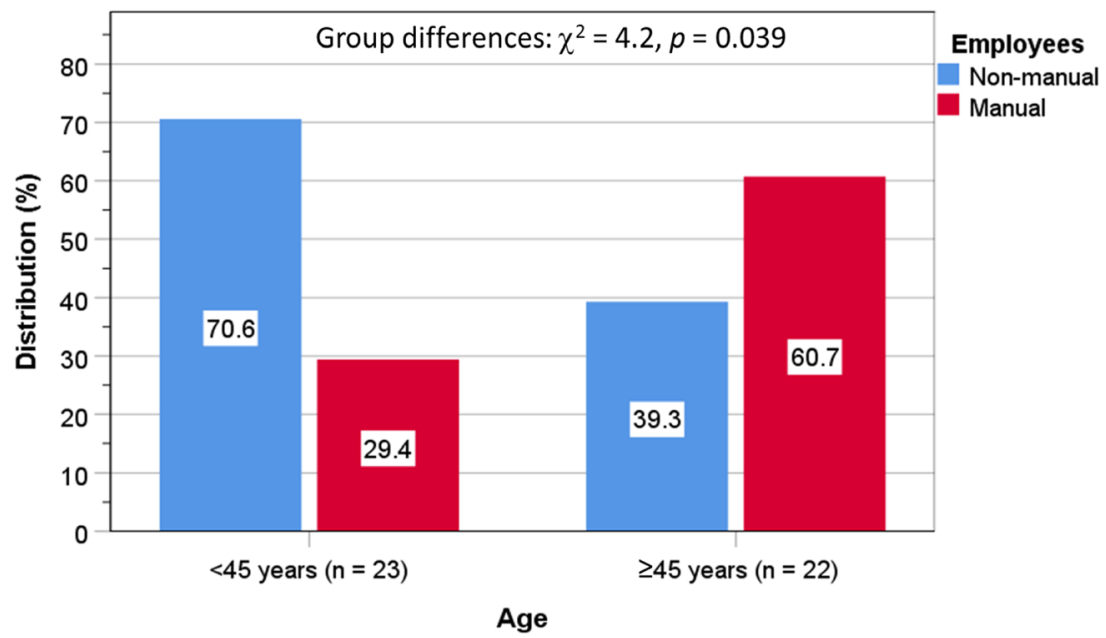

(B)

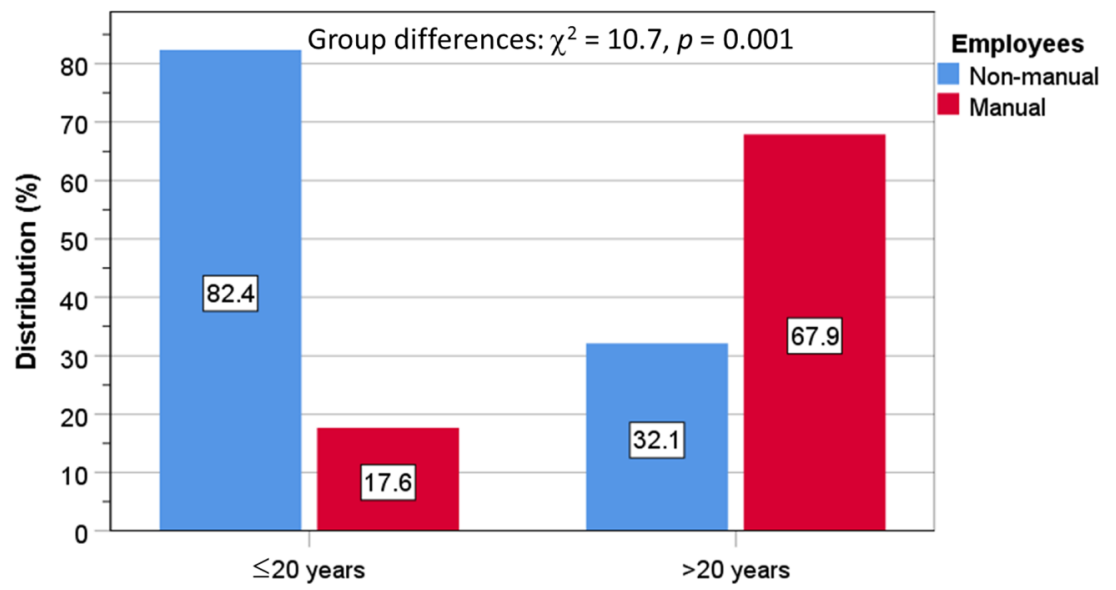

Length of time working in construction industry

Table 3 Differences in health risk between construction workers

\begin{tabular}{|c|c|c|c|c|c|c|c|c|}
\hline & \multicolumn{4}{|c|}{ Occupational status } & \multicolumn{4}{|c|}{ Breathing problems } \\
\hline & \multirow{2}{*}{$\begin{array}{l}\text { Non-manual } \\
\%\end{array}$} & \multirow{2}{*}{$\begin{array}{l}\text { Manual } \\
\%\end{array}$} & \multicolumn{2}{|c|}{ Group differences } & \multirow{2}{*}{$\begin{array}{l}\text { No } \\
\%\end{array}$} & \multirow{2}{*}{$\begin{array}{l}\text { Yes } \\
\%\end{array}$} & \multicolumn{2}{|c|}{ Group differences } \\
\hline & & & $x^{2}$ & $p$ & & & $x^{2}$ & $p$ \\
\hline Length of time working in construction industry $>20$ years & 17.6 & 67.9 & 10.7 & 0.001 & 36.7 & 73.3 & 5.4 & 0.020 \\
\hline Exposure to silica dust and smoking & 5.9 & 50.0 & 9.3 & 0.002 & 23.5 & 53.3 & 4.1 & 0.044 \\
\hline $\begin{array}{l}\text { Personal protective equipment } \\
\text { (provided and use and advice) }\end{array}$ & 58.8 & 28.6 & 4.0 & 0.045 & 50.0 & 20.0 & 3.8 & 0.050 \\
\hline $\begin{array}{l}\text { Awareness of silicosis } \\
\text { (heard of silicosis and no silicosis diagnosis) }\end{array}$ & 64.7 & 64.3 & 0 & 0.977 & 60.0 & 73.3 & 0.8 & 0.294 \\
\hline $\begin{array}{l}\text { Information on health hazards } \\
\text { (safeguards and health education) }\end{array}$ & 58.8 & 28.6 & 4.0 & 0.045 & 53.3 & 13.3 & 6.7 & 0.010 \\
\hline Regular health checks provided by company & 41.3 & 17.9 & 2.9 & 0.086 & 33.3 & 13.3 & 2.0 & 0.141 \\
\hline Working for company $>1000$ employees & 52.9 & 28.6 & 2.7 & 0.094 & 43.3 & 26.7 & 1.2 & 0.225 \\
\hline Breathing problems & 0.0 & 53.6 & 13.7 & $<0.001$ & - & - & - & - \\
\hline
\end{tabular}


there were fewer amongst those with breathing problems who reported having PPE provided by company, used PPE or advised others to use PPE ( $50 \%$ vs $20 \%, \chi^{2}=3.8, p=0.050$ ), and who had adequate safeguards and education $(53.3 \%$ vs $13.3 \%, \chi^{2}=6.7, p=0.010$ ). There were no differences in awareness of silicosis, regular health checks provided by company or if working for a company with $>1000$ employees (Table 3).

Logistic regression analysis showed that compared to non-manual workers, manual workers were more likely to work longer than 20 years in construction industry where they would be exposed to RCS: $\mathrm{OR}=2.2(95 \% \mathrm{CI}=1.3-3.6)$, be exposed to dust and smoke cigarettes: age and length of time working in construction industry adjusted $\mathrm{OR}=2.2(1.2-4.2)$. They were also more likely to have breathing problems: age, smoking and length of time working in construction industry adjusted $\mathrm{OR}=3.7(1.1-12.5)$. The risk of breathing problems was also increased for individuals working in construction industry more than 20 years: $\mathrm{OR}=4.8(1.2-18.6)$, or exposed to dust and smoking: age and length of time working in construction industry adjusted: $\mathrm{OR}=5.4$ (1.2-24.4). Those with adequate information on health hazards were associated with lower risk of breathing problems (Table 4).

\section{Discussion}

Our study has revealed that manual workers continue to face a number of work-related adverse factors that could potentially contribute a health risk. Compared to non-manual workers, greater proportions of manual workers complained of breathing problems. Manual workers with breathing problems are more likely to: be exposed to greater health risks at work, smoke, be less aware of and use PPE, advise others less to use PPE, and be less aware of safeguards and health risk education. Given a large workforce of 2.3 million employees in the construction industry (Green 2000), the scale of health risk from RCS is potentially very significant. These findings suggest greater protection and/or education is needed for manual workers to minimise these risks.

The observation of younger age and shorter length of time working in construction industry among non-manual workers suggests that this group of employees may have better job opportunities and promotions, leading to greater movement between jobs. On the other hand, the older age and longer length of time working in construction industry of manual workers indicate that this group of employees do not have the opportunity to move upwards to management level or move to a different job with less exposure to dusty environments. Consequently, manual workers are subject to prolonged and sustained period of exposure to silica dust. Therefore, it is important that risk factors for manual workers should be continuously re-assessed and action taken to improve their health.

The high prevalence of manual workers exposed to dusty environments is consistent with previous reports in industrialised countries (Rappaport et al. 2003). The combination of a lengthy time working in construction industry, greater exposure to dusty environments and cigarette smoking among manual workers potentiates their health risk, as seen in their high prevalence of breathing problems. An important question is if the larger incidence of breathing problems in manual workers was independent of their increased incidence of smoking. Further analysis showed that even after taking age

Table 4 Risk factors associated with manual employees and breathing problems

\begin{tabular}{|c|c|c|c|c|c|c|}
\hline & \multicolumn{3}{|c|}{ Manual workers* } & \multicolumn{3}{|c|}{ Breathing problems ${ }^{\dagger}$} \\
\hline & OR & $95 \% \mathrm{CI}$ & $p$ & OR & $95 \% \mathrm{CI}$ & $p$ \\
\hline Length of time working in construction industry $>20$ years & 2.2 & $1.3-3.6$ & 0.003 & 4.8 & $1.2-18.6$ & 0.025 \\
\hline Exposure to dust and smoking & 1.8 & $1.1-3.1$ & 0.029 & 3.8 & $1.0-14.1$ & 0.050 \\
\hline $\begin{array}{l}\text { Exposure to dust and smoking (adjusted for age and length of time working in construction } \\
\text { industry) }\end{array}$ & 2.2 & $1.2-4.2$ & 0.012 & 5.4 & $1.2-24.4$ & 0.030 \\
\hline $\begin{array}{l}\text { Personal protective equipment } \\
\text { (provided and use and advice) }\end{array}$ & 0.76 & $0.51-1.13$ & 0.180 & 0.25 & $0.06-1.07$ & 0.062 \\
\hline $\begin{array}{l}\text { Awareness of silicosis } \\
\text { (heard of silicosis and no silicosis diagnosis) }\end{array}$ & 0.96 & $0.64-1.44$ & 0.845 & 1.83 & $0.47-7.13$ & 0.382 \\
\hline $\begin{array}{l}\text { Information on health hazards } \\
\text { (safeguards and health education) }\end{array}$ & 0.70 & $0.47-1.05$ & 0.085 & 0.14 & $0.03-0.70$ & 0.017 \\
\hline Regular health checks provided by company & 0.70 & $0.45-1.08$ & 0.104 & 0.31 & $0.06-1.64$ & 0.167 \\
\hline Working for company $>1000$ employees & 0.71 & $0.47-1.06$ & 0.096 & 0.48 & $0.12-1.84$ & 0.282 \\
\hline Breathing problems & 3.9 & $1.5-10.4$ & 0.007 & - & - & - \\
\hline $\begin{array}{l}\text { Breathing problems (adjusted for age, smoking and length of time working in construction } \\
\text { industry) }\end{array}$ & 3.7 & $1.1-12.5$ & 0.038 & - & - & - \\
\hline
\end{tabular}

Reference groups: *non-manual workers; ${ }^{\dagger}$ no breathing problems 
and smoking history into account, manual workers indeed continued to have an increased risk of breathing problems. This suggests that with manual workers work-related exposure to silica dust is an independent risk for the development of respiratory conditions.

Like asbestosis, silicosis is an incurable disease which may persist and progress beyond the cessation of exposure to RCS (Wagner 1997). Rigorous protection and preventative measures are therefore important. Since silicosis is related to the cumulative product of the concentration and duration of RCS exposure, a periodic change in work roles within the company to allow high risk workers rest from less dusty environments may help reduce long-term health risk. This technique of job rotation scheduling has been adopted to reduce repetitive work-related injuries (Leider et al. 2015; Otto and Battaïa 2017).

The availability of PPE provided to the workers by the company and their willingness to use it when available were both reported as proportionally lower among manual workers. A recent review found that although PPE is readily provided by companies, improper use of PPE is frequently observed on construction sites (Ammad et al. 2020). There was also a lower proportion of manual workers who reported adequate safeguards to ensure that you take protective action when working with silica dust, and education in place for employees to recognise breathing health hazards. It is the responsibility of line-managers to reinforce and encourage the use of PPE by manual workers (Wong et al. 2021), including the provision of adequate safeguards and education on health risks.

The risks of silicosis were understood equally by manual and non-manual employees in the present study. A survey conducted by the IOSH (2021) reported only $27.8 \%$ of workers were aware of silicosis associated with dust from construction sites, which is substantially lower than our figure of $80 \%$. This may suggest that recent educational efforts are improving awareness of silicosis, but poor uptake of protective measures, such as the effective use of PPE, is still having adverse effects on workers' health.

Manual workers engaged in poor health life-style choices was demonstrated by a higher prevalence of cigarette smoking, a well-recognised risk factor for respiratory disease. These findings are consistent with reports among construction workers in the US (Bang and Kim 2001). Studies have shown that efforts to make construction sites smoke-free zones to be highly challenging (Bondy and Bercovitz 2011). We only assessed smoking history but is important to record also other aspects of lifestyle such as alcohol history, diet and exercise and stress levels among these workers as part of their regular health checks.

The study is limited by a small sample size. Bias may have been introduced by those who did not have access to computers and as with studies using questionnaires, reporting bias may have occurred. There is a lack of published questionnaires for this type of study. Although we have purposefully worded the questions in simple layman's terms, our questionnaires used only the English language which might have biased against non-English speaking people. Further studies are necessary to validate our questionnaires. Similar to other surveys using questionnaires, we relied on the participants' honesty in answering the questions. However, we feel that those who took time to participate in the survey would likely to be motivated and interested in research to improve the environment and health. We did not ask where the participants were located but they were probably from English-speaking countries. We did not ask for specific company details, except the size of the company they were employed at the time to address the specific question about whether participant awareness of risk factors might be different between large and smaller companies. The health, safety and environment policies may therefore have been varied between companies. All these factors may have some impact on the findings of this study. We were not able to explain the relatively low number of participants $(n=47)$ given the large number of registered users (possible 25,000). There may be a number of possible reasons including: "survey fatigue"; lack of incentives as there were no immediate rewards for participation, lack of interest in the question; or lack of access to websites.

\section{Conclusions}

The findings of this study have revealed that despite construction workers' improved awareness of the adverse effects of silicosis, their increased risk of exposure to RCS dust and pulmonary symptoms has persisted. More efforts are needed to provide greater protection and improved education at the effective use of PPE for this group of workers to reduce their health risk. Greater health promotion and protection, especially directed at manual workers, may reduce health inequalities amongst employees in the construction industry.

Authors' contributions $\mathrm{BF}$ and $\mathrm{LM}$ reviewed the topic related literature and performed the study concept. BF collected the data. TSH performed data analysis. BF and TSH wrote the first draft of the paper. DF and CHF edited the manuscript. All authors checked, interpreted results and approved the final version.

\section{Declarations}

Conflict of interest The authors declare that they have no conflicts of interest.

Statement of human and animal rights This article does not contain any studies with animals performed by any of the authors. 
Open Access This article is licensed under a Creative Commons Attribution 4.0 International License, which permits use, sharing, adaptation, distribution and reproduction in any medium or format, as long as you give appropriate credit to the original author(s) and the source, provide a link to the Creative Commons licence, and indicate if changes were made. The images or other third party material in this article are included in the article's Creative Commons licence, unless indicated otherwise in a credit line to the material. If material is not included in the article's Creative Commons licence and your intended use is not permitted by statutory regulation or exceeds the permitted use, you will need to obtain permission directly from the copyright holder. To view a copy of this licence, visit http://creativecommons.org/licenses/by/4.0/.

\section{References}

Akbar-Khanzadeh F, Brillhart RL (2002) Respirable crystalline silica dust exposure during concrete finishing (grinding) using hand-held grinders in the construction industry. Ann Occup Hyg 46(3):341346

Ammad S, Alaloul WS, Saad S, Qureshi AH (2020) Personal protective equipment (PPE) usage in construction projects: a Scientometric approach. J Building Eng 11:102086

Bang KM, Kim JH (2001) Prevalence of cigarette smoking by occupation and industry in the United States. Am J Ind Med 40(3):233-239

Bondy SJ, Bercovitz KL (2011) Non-smoking worksites in the residential construction sector: using an online forum to study perspectives and practices. Tob Control 20(3):189-195

Flanagan ME, Seixas N, Majar M, Camp J, Morgan M (2003) Silica dust exposures during selected construction activities. AIHA J 64(3): 319-328

Greenberg MI, Waksman J, Curtis J (2007) Silicosis: a review. Dis Mon 53:394-416

Health and Safety Executive (2021) Cancer and construction: Silica. https://www.hse.gov.uk/construction/healthrisks/cancer-andconstruction/silica-dust.htm (Accessed March, 2021)
The IOSH (2021) Construction Group Committee. Construction dust: An industry survey. http://www.iosh.co.uk/dust (Accessed March, 2021)

Leider PC, Boschman JS, Frings-Dresen MH, van der Molen HF (2015) When is job rotation perceived useful and easy to use to prevent work-related musculoskeletal complaints? Appl Ergon 51:205-210

Leung CC, Yu IT, Chen W (2012) Silicosis. Lancet 379(9830):20082018

Otto A, Battaïa O (2017 Sep 1) Reducing physical ergonomic risks at assembly lines by line balancing and job rotation: a survey. Comput Ind Eng 111:467-480

Occupational Safety and Health Administration (2016) Occupational exposure to respirable crystalline silica. Final rule Federal register 81 (58):16285-16890

Rappaport SM, Goldberg M, Susi PA, Herrick RF (2003) Excessive exposure to silica in the US construction industry. Ann Occup Hyg 47(2):111-122

Rice FL, Park R, Stayner L, Smith R, Gilbert S, Checkoway H (2001) Crystalline silica exposure and lung cancer mortality in diatomaceous earth industry workers: a quantitative risk assessment. Occup Environ Med 58(1):38-45

Steenland K, Sanderson W, Calvert GM (2001) Kidney disease and arthritis in a cohort study of workers exposed to silica. Epidemiology 1:405-412

Steenland K, Sanderson W (2001) Lung cancer among industrial sand workers exposed to crystalline silica. Am J Epidemiol 153(7):695703

Green B (2000) The real face of construction 2020: socioeconomic analysis the true value of the built environment. Chartered Institute Build (CIBO)

van Thienen G, Spee T (2008) Health effects of construction materials and construction products. J App Occup Sci 14(13):2-3

Wagner GR (1997) Asbestosis and silicosis. Lancet 349(9061):13111315

Wong TK, Man SS, Chan AH (2021) Exploring the acceptance of PPE by construction workers: an extension of the technology acceptance model with safety management practices and safety consciousness. Ssafety Science 139:105239 